\title{
A ascensão da China e seus reflexos no Brasil: fundamentos e evidências para uma estratégia de desenvolvimento
}

Diego Bonaldo Coelho*

Gilmar Masiero**

Luiz Caseiro ${ }^{* * *}$

Recebido: 31/07/2014 Versão Revisada (entregue): 17/02/2015 Aprovado: 24/02/2015

\section{Resumo}

$\mathrm{O}$ artigo analisa os fundamentos da estratégia nacional de desenvolvimento da China, que permitiram ao país se tornar um dos principais centros de gravidade da economia internacional, em trajetória que promoveu diversos impactos nas demais economias e tem pressionado a reestruturação da agenda de desenvolvimento dos países a partir de uma nova realidade global. Com fundamentação teórica e estatística, o trabalho apresenta evidências da ascensão da economia chinesa, de seus fundamentos e de seus impactos na economia brasileira. Diante da análise dos dados e da experiência chinesa, sugere-se a necessidade de o Brasil elaborar uma estratégia nacional que seja fundamentada na articulação institucional de políticas, na internacionalização e na inovação de sua economia.

PALAVRAS-CHAVE | Estratégia Nacional de Desenvolvimento; China; Brasil; Políticas Industriais

Códigos JEL | O14; O21; O38; O57

\footnotetext{
* Escola Superior de Propaganda e Marketing (ESPM) e Pontifícia Universidade Católica de São Paulo (PUC-SP), São Paulo (SP), Brasil. E-mail: diego.coelho@espm.br

** Universidade de São Paulo (USP), São Paulo (SP), Brasil. E-mail: gilmarmasiero@gmail.com

*** Universidade de São Paulo (USP), São Paulo (SP), Brasil. E-mail: luizzalaf@gmail.com
} 


\section{The rise of China and its reflexes in Brazil: rationale and evidences for a development strategy}

\section{ABSTRACT}

This paper analyzes the fundamentals of the Chinese national development strategy that have transformed China into a major gravity center of the world economy. China's rise not only promoted several impacts on other economies, but it also has led to the restructuring of their development agenda. Through robust theories and statistics, this paper delves deeper on the determinants China's rise and its impacts on the Brazilian economy. From this analysis, we suggest the need for Brazil to develop a national strategy that is grounded in an institutional policy mix that promotes the internationalization and innovation of its economy.

KeYwords | National Development Strategy; China; Brazil; Industrial Policy

JEL-CODES | O14; O21; O38; O57 


\section{Introdução}

Por mais de um século, desde a Primeira Revolução Industrial até as crises do petróleo na década de 1970, o Atlântico norte foi o principal motor da economia global. Entre 1870 e 1972, a Europa e a América do Norte responderam por aproximadamente dois terços do crescimento do Produto Interno Bruto (PIB) mundial (BOLT; ZANDEN, 2013). Entretanto, no período de 2002 a 2012 esse valor foi reduzido para $36 \%$, enquanto a participação dos países do leste e sudeste asiático chegou a 44\% (WORLD BANK, 2013). Esses números evidenciam o deslocamento do centro de gravidade da produção mundial e prenunciam alterações na dinâmica de poder, na distribuição da renda e na lógica de conformação das cadeias globais de valor, cujos resultados podem ser percebidos nos indicadores internacionais da produção científica, no número de patentes e no número das maiores empresas globais, os quais revelam a importância do crescimento asiático na prestação de serviços e produção de bens e de conhecimento (GAO, 2011; MAcDONALD; LEMCO, 2011).

Contudo, ainda que se destaque a região asiática, um país, em particular, é proeminente: a China. Grande parte da reconfiguração da geografia econômica global da última década encontra nesse país as suas principais determinantes, cuja magnitude de ascensão econômica não tem precedentes. Enquanto a média do crescimento mundial foi de 3\% entre 1990 e 2010, a China atingiu 10\% nesse mesmo período. Um ritmo que repercutiu em vários indicadores daquele país. Em 1990, por exemplo, os chineses possuíam uma renda per capita de US\$392, valor que representava $9 \%$ do mundial e $12 \%$ do brasileiro (WORLD BANK, 2013). Porém, em 2010, a distribuição nacional de sua renda per capita saltou para US\$ 2.425, evolução que permitiu à China retirar aproximadamente 500 milhões de pessoas da pobreza extrema (WORLD BANK, 2012). De uma economia pouco significativa em 1990, o país tornou-se o maior exportador mundial e o segundo destino de Investimento Direto Estrangeiro (IDE) na década de 2000 (UNCTAD, 2010; WTO, 2012).

A China rapidamente se tornou um importante vetor das dinâmicas político-econômicas globais e tem atraído crescente interesse do mundo acadêmico e empresarial. Assim, neste estudo, coloca-se a seguinte questão: é possível pensar o momento brasileiro contemporâneo a partir das experiências chinesas? A questão é pertinente, pois a China não se trata apenas de uma ascensão enigmática entre os 
países em desenvolvimento, mas também cuja trajetória tem impactado fortemente as demais economias, com destaque para a brasileira.

Nesse contexto, o principal objetivo do presente estudo é identificar os fundamentos do crescimento chinês e seus impactos no Brasil, não apenas para evidenciar a experiência chinesa, mas, principalmente, para utilizá-la como fio condutor para pensar a economia brasileira atual e sua trajetória. Busca-se, nesse sentido, fornecer elementos para a elaboração de uma estratégia brasileira de desenvolvimento, apesar da China, com a China, mas não sem a China (MASIERO et al., 2012). Nesses termos, para a consecução de seus fins, o artigo está organizado da seguinte maneira: primeiramente, qualifica-se a trajetória chinesa, buscando identificar seus elementos determinantes; em seguida, são analisados os principais impactos da trajetória chinesa na economia brasileira; e, nas conclusōes, sugerem-se fundamentos da experiência asiática que podem ser incorporados ao marco de elaboração de uma estratégia nacional de desenvolvimento.

\section{Ascensão chinesa contemporânea: Estado, política industrial e crescimento econômico}

A análise detalhada do PIB chinês permite pensar os fundamentos de sua trajetória ascendente na virada para o século XXI, quando se constatam a importância e o lugar privilegiado ocupado pela indústria no crescimento nacional. Entre 1990 e 2009, nota-se que o setor agrícola reduziu sua participação no produto nacional, ao passo que o de serviços aumentou seu peso, sendo que a indústria se manteve preponderante. Em termos relativos, enquanto a China atingiu média de $46 \%$ de participação da indústria em seu PIB entre 1990 e 2009, a média brasileira para o mesmo período foi de 30\% e a mundial correspondeu a 29\% (WORLD BANK, 2013).

Ao focar a indústria manufatureira, entendida como os grupos entre 15 e 37 da International Standard Industrial Classification (ISIC), observa-se que este é o setor que tem contribuído para o forte crescimento do valor agregado industrial chinês. No agregado de 1990 a 2009, a participação média da indústria manufatureira no PIB chinês foi de 33\% - a maior entre os países em desenvolvimento (WORLD BANK, 2013). Uma das explicações para a expressiva participação da indústria manufatureira na economia chinesa, em relação ao observado na maior parte de outras economias, está, basicamente, na forte expansão da capacidade produtiva por meio de investimentos. A Formação Bruta de Capital Fixo (FBCF) da China apresentou variação média anual positiva de 9\% entre 1990 e 2009. Para efeitos 
comparativos, o Brasil e o mundo registraram apenas $2 \%$ para o mesmo período (WORLD BANK, 2013).

Pelas estatísticas apresentadas, torna-se evidente que a indústria chinesa assumiu uma importante função na promoção do crescimento econômico nacional. Esse fenômeno revela um forte alinhamento da realidade econômica chinesa com a perspectiva teórica que indica o papel fundamental da industrialização no crescimento nacional. Como demonstraram Amsden (2009), Krüger (2008), Soete (2007) e Evans (2004), a dinâmica do crescimento tende a ocorrer por meio da realocação dos fatores de atividades de baixa produtividade para os de alta produtividade, em um processo no qual o setor industrial é fundamental. É ele que comporta o maior potencial de incrementos da produtividade, dados os seus componentes tecnológicos, encadeamentos intra e intersetoriais e externalidades pecuniárias.

Nesse sentido, a industrialização também adquire centralidade em uma economia global, pois, uma vez que as cadeias de produção, distribuição e prestação de serviços são estendidas por meio das fronteiras nacionais, o processo de industrialização capaz de elevar a produtividade de determinado país - ou, mais precisamente, de regiôes específicas dentro de seu território - não ocorre de forma independente das dinâmicas internacionais de produção. As diversas regiões do globo encontram-se inseridas em uma divisão internacional do trabalho, impactando-se mutuamente. Porém, é importante ressaltar que a simples lógica de alocação dos investimentos de acordo com as vantagens comparativas existentes, ou seja, por meio das dinâmicas exclusivamente de mercado, é uma força que tende a reforçar a estrutura da divisão internacional do trabalho vigente.

Em termos teóricos, há certa retomada contemporânea de vertente analítica que sublinha a importância da atuação do Estado (CASTELLS, 1999; DICKEN, 2010; NOLAN, 2001; RODRIK, 2004), especificamente nos países em desenvolvimento. Trata-se de perspectivas que preconizam parcerias do Estado com a iniciativa privada por meio de políticas industriais, com objetivo de criar novas vantagens comparativas capazes de atrair fluxos de investimentos para indústrias mais dinâmicas e intensivas em conhecimento, uma vez que estas possuem produtividade mais elevada, pagam melhores salários e possibilitam spillovers tecnológicos para outras empresas e desenvolvimento de novos fornecedores.

São aspectos que se tornam relevantes à reflexão, tendo em vista que, a partir do final dos anos 1980, o cenário político-econômico internacional passou a ser fortemente marcado pelo pensamento liberal. Nesse período, como destacou Buira (2004), negou-se à maior parte dos governos qualquer papel ou ação mais incisiva 
na promoção do desenvolvimento de setores industriais, sendo descartada qualquer forma de política industrial. Não ocasionalmente, ao longo dos anos 1990, mais de 49 países iniciaram seu processo de abertura econômica. Muitos deles optaram por adotar prescrições do Consenso de Washington, dando proeminência às forças de mercado em detrimento das intervenções governamentais para promoção do desenvolvimento (RODRIGUEZ, 2007).

Todavia, a argumentação adotada no presente artigo alinha-se tanto à experiência chinesa quanto à perspectiva teórica que retoma a relevância do ator governamental na competitividade nacional diante da economia global. Afinal, apesar de as cadeias produtivas encontrarem-se internacionalizadas, o espaço nacional preserva influência decisiva para a atuação empresarial, em virtude de os arranjos institucionais e padrōes culturais definirem as condiçōes de aprendizado e o poder de sanção dos atores sociais (HALL; SOSKICE, 2001). Nesses termos, a indústria deve ser pensada como um setor-chave para as estratégias nacionais de desenvolvimento, da mesma maneira que se deve enfatizar a importância da atuação governamental para a criação de vantagens comparativas dinâmicas em indústrias intensivas em conhecimento por meio de políticas industriais, sem, contudo, restringir sua ação apenas a ações e regulamentações protecionistas de longa duração.

Trata-se, portanto, de uma perspectiva teórica que relaciona o desenvolvimento econômico aos diferentes padrões de integração nos mercados globais e, simultaneamente, à transformação estrutural do tecido produtivo nacional por meio da ação governamental. Assim, tal abordagem, embora retome em seu seio uma influência estruturalista, atualmente é relida por uma ótica concorrencial e de integração, como proposto por Porter (1989), Vietor (2007), Wade (2010), entre outros, afastando-se dos modelos estáticos de substituição das importações.

\section{Fundamentos da estratégia chinesa de desenvolvimento}

Como revela a história econômica chinesa, a relação entre industrialização e planejamento nacional começou a ganhar seus primeiros contornos a partir das reformas políticas e econômicas levadas a cabo no país em 1978. Contudo, esse processo só se tornou evidente e delineado em 1989, quando o Conselho de Estado emitiu pela primeira vez em seus Planos Quinquenais as diretrizes para uma política industrial - decisão divergente ao mainstream econômico internacional da época.

A motivação do governo para a formulação de uma política industrial decorreu dos problemas vivenciados pela estrutura industrial chinesa naquela época, que 
chegou ao final dos anos 1980 com discrepâncias que se colocavam como entraves ao seu desenvolvimento, das quais destacam-se: excesso da capacidade de produção, desproporcional ao lento desenvolvimento dos setores agrícola, energético, de transporte e extrativo mineral; disparidade entre o desenvolvimento da indústria de nível médio vis-à-vis ao débil desenvolvimento da indústria avançada; distribuição regional irracional das indústrias e subutilização de vantagens comparativas regionais; fraco empenho e capacidade de coordenação e organização entre as empresas; e pouca concentração e eficiência industrial (MARRONE, 2006).

Diante desse cenário, o governo chinês optou por formular uma política industrial de longo prazo, seletiva e orientada para a consolidação de setores considerados prioritários - como os de alta tecnologia e os capital-intensivos, importantes para adicionar e avançar nas cadeias de valor (NOLAN, 2001). O desenvolvimento de tais setores, a partir da intervenção do governo sobre os negócios, foi planejado, mas não de forma isolada, uma vez que teve sua consolidação combinada e articulada com outras políticas governamentais. As bases dessa estratégia industrial e de sua articulação nacional foram estabelecidas no Plano Decenal (1991-2000), sendo especificamente detalhadas nas Diretrizes de Política Industrial para os anos 1990. Já as ações de consecução de tais diretrizes foram dadas pelos dois planos quinquenais do período: o 8o, de 1991 a 1995, e o 9o, de 1996 a 2001, sendo aprofundadas, com maior ênfase setorial, nos planos subsequentes, o $10^{\circ}$, de 2001 a 2005 , e o $11^{\circ}$, de 2006 a 2010.

Pela análise dos conteúdos de cada plano, verifica-se que os chineses decidiram iniciar, nos anos 1990, um processo de redirecionamento de sua industrialização por meio do planejamento de uma política industrial, cujos focos não seriam apenas o atendimento do mercado interno, mas, primordialmente, a inserção internacional. O seu marco institucional e estratégico não se tratou somente de uma política industrial típica, mas também de uma orientação articulada em várias frentes e políticas governamentais, tais como de comércio exterior, cambial e de atração de investimentos diretos estrangeiros, com objetivo de tornar sua indústria competitiva internacionalmente.

Diversas políticas e programas específicos para cada setor prioritário foram estabelecidos pela Comissão Nacional de Desenvolvimento e Reforma (CNDR), responsável pelo gerenciamento da política industrial do país. A descrição detalhada de cada um dos programas e políticas pode ser encontrada em estudos realizados pelo BNDES (2009), pela ABDI (2011) e Masiero e Coelho (2014). Em linhas gerais, tais diretrizes podem ser descritas da seguinte forma: nos setores tradicionais, intensivos em mão de obra (couro e calçados, madeira e móveis, têxtil etc.), o governo 
chinês buscou incentivar a modernização, a melhoria da qualidade dos produtos e a redução do impacto ambiental. A maior parte dos incentivos, entretanto, destinou-se aos setores intensivos em capital e conhecimento, com destaque às indústrias de bens de capital, automotiva, naval, aeronáutica, tecnologias da informação e comunicação e o complexo industrial de saúde. Nesses setores, o governo buscou a consolidação de grandes empresas com competitividade internacional (sempre mais de uma por setor, de forma a diversificar os riscos e estimular a concorrência interna), a ampliação da taxa de retorno sobre o capital, o incentivo ao investimento em P\&D\&I e a modernização da gestão corporativa.

Diversas medidas foram adotadas com tais propósitos: concomitantemente ao incentivo ao investimento direto estrangeiro, foram impostos limites à participação estrangeira nas joint-ventures (50\% para o complexo automotivo e $25 \%$ no aeronáutico); proibição de as empresas estrangeiras estabelecerem mais de duas joint-ventures para o mesmo produto; restrições à importação de bens produzidos localmente, especialmente no caso de bens usados; obrigatoriedade de adequação às normas internacionais simultaneamente ao incentivo para a criação de design independente; criação de grandes projetos estruturantes em cada setor (como no caso da indústria naval, com foco da produção de grandes navios graneleiros, petroleiros e porta-contêineres); e obrigatoriedade de a produção de empresas chinesas ostentar a marca local (ABDI, 2011).

Desse modo, é possível afirmar que as transformaçōes verificadas na estrutura industrial chinesa são decorrentes dessa articulação de políticas governamentais, a qual pode ser tomada como um dos fatores determinantes de sua estratégia contemporânea de desenvolvimento, pautada, em grande parte, na busca de uma inserção internacional que ficou conhecida na literatura internacional como going global (UNCTAD, 2006; WORLD BANK, 2012; MASIERO; COELHO, 2014). Essa estratégia tornou-se explícita em 2001, quando o governo chinês iniciou vigorosa e agressiva internacionalização de sua economia, tanto de "fora para dentro", na recepção de investimentos e importação, quanto de "dentro para fora", por meio da realização de investimentos externos e exportações.

Os resultados não tardaram. Já em 2009, a economia chinesa tornou-se o segundo maior destino de investimentos produtivos do mundo, da mesma forma que sua indústria atingiu a sexta posição entre os maiores investidores produtivos (UNCTAD, 2010). Tanto na atração dos investimentos quanto no estímulo ao investimento das empresas chinesas no exterior, nota-se uma atuação incisiva do Estado na definição de setores prioritários. Várias instituiçôes governamentais foram 
articuladas nesse processo, com atuação subordinada e capitaneada pelo Conselho de Estado, o qual elaborou diretrizes para o investimento externo, que podem ser resumidas em três principais objetivos: acessar recursos naturais escassos no país; fomentar a industrialização e o desenvolvimento tecnológico das empresas nacionais; e aumentar a competitividade das empresas chinesas por meio da promoção de marcas no exterior e da construção de uma rede global de produção e fornecimento (CASEIRO; MASIERO, 2014).

No âmbito comercial, a China também sofreu alterações consideráveis ao longo das últimas duas décadas como fruto de sua estratégia nacional articulada. A expansão comercial chinesa foi realizada por meio da oferta de produtos manufaturados de crescente valor agregado, com potencial de aceitação em mercados diversificados e competitivos. Em curto espaço de tempo, os chineses atingiram o primeiro lugar no ranking de exportadores, ultrapassando, ainda em 2009, a tradicional posição ocupada pela Alemanha. Trata-se de uma expansão vigorosa não apenas em quantidade e volume, mas também nas categorias de produtos que compóem a sua pauta, que passa a ser majoritariamente de manufaturados difusores de tecnologia, como eletroeletrônicos e bens de capital. Assim, o padrão comercial chinês, que era, em 1991, de 22,5\% de bens primários e 77,5\% de manufaturados do total exportado, passou, em 2008, para 5,5\% de primários e 94,5\% de manufaturados (CSY, 2009) - máquinas e equipamentos, por exemplo, que representavam 9,9\% dos produtos exportados em 1991, respondiam por 47,1\%, em 2008.

Tais modificações na estrutura industrial chinesa desenvolveram um novo contexto para o país, pois, se até meados dos anos 2000 os agentes internacionais apenas vislumbravam a China como uma vantagem locacional atrativa devido aos baixos salários e aos incentivos governamentais, sendo as empresas locais vistas como meras implementadoras de suporte, os resultados alcançados pela sua acelerada industrialização passaram a apontar para outras direçōes. Embora sua mão de obra ainda hoje seja relativamente competitiva internacionalmente, é notório que o crescimento da indústria chinesa também avança em outras frentes, destacadamente aquelas de maior valor agregado: com qualidade, tecnologia e inovações locais nativas (denominadas indigenous innovation) (MIAO; WEI; MA, 2007).

Competidores nacionais chineses surgiram rapidamente, com flexibilidade e agilidade, disputando parcelas significativas de seu crescente mercado doméstico e outras do mercado internacional (GHEMAWAT; HOUT, 2008; ZENG; WILLIAMSON, 2007; BHATTACHARYA; MICHEL, 2008). Essa participação pode ser verificada também na lista Fortune Global 500, que ranqueia as 500 maiores 
empresas do mundo. Em 2005, a China detinha 16 empresas neste ranking, mas, em 2014, esse número saltou para 95 - crescimento de 493,75\%. Para efeitos de comparação, o Brasil possuía, em 2005, duas empresas listadas na Fortune Global 500, aumentando para sete, em 2014.

Como consequência, a percepção de produtos "made in China" a "preços chineses", isto é, de baixa qualidade, baratos, fabricados por empresas estrangeiras ou ainda por chinesas pouco experientes em manufatura, aos poucos migra para a constatação de produtos desenvolvidos e criados na China, com valores adicionados no país, por meio de inovações em processos e tecnologia, não apenas por multinacionais de países desenvolvidos, mas também por um crescente número de empresas genuinamente chinesas. Com isso, a China torna-se não apenas o workshop of the world (GAO, 2011) de fornecimento de mão de obra ao mundo, mas também um player competitivo em tecnologia, inovação e valor agregado.

Essa tendência pode ser verificada em diversos casos empresariais de setores de alta tecnologia, tais como: a expansão da Haier no mercado mundial de eletrodomésticos; a Galanz com mais da metade do mercado global de micro-ondas; a ChinaMedical como líder mundial no desenvolvimento de ultrassom; a BYD como a maior fabricante do mundo de baterias recarregáveis; a Vimicro com mais de 60\% do mercado internacional de processadores multimídia; a Lenovo como uma das maiores fabricantes global de computadores pessoais; e, como em outros casos, a ascensão da Huawei e da ZTE entre os principais produtores de equipamentos de telecomunicação (ZENG; WILLIAMSON, 2007; NOLAN, 2014).

Assim, é possível afirmar que as empresas chinesas promoveram grande ruptura de trajetória histórica em seu desenvolvimento. Para Zeng e Williamson (2007), a indústria chinesa contribui em vários processos de manufatura com destacado know-how em inovar maneiras de se entregar altas tecnologias com baixo custo, com base em inovaçōes em processos e produtos e não necessariamente baixos salários. Esse processo representa uma vantagem e um diferencial competitivo que foram atingidos tanto pelo processo qualificado de políticas públicas articuladas quanto pelas próprias características de seu mercado interno (altamente demandante e de poder aquisitivo crescente).

\section{A China e seus reflexos no Brasil}

Os reflexos da industrialização e expansão internacional chinesa são evidentes em qualquer parte do mundo e também no Brasil. Pela ótica comercial, ainda que se 
note uma intensificação das relações comerciais sino-brasileiras desde 1990, forte boom é constatado a partir dos anos 2000, em que, de uma corrente de comércio de US\$ 2,3 bilhões, saltou-se para a marca de US\$ 77,3 bilhões em 2013 (BRASIL, 2014). Dessa forma, a corrente de comércio do Brasil com a China, que representava $2 \%$ do total da brasileira em 2000, passou a ser de 29,5\% em 2013, possibilitando aos chineses assumir atualmente a posição de principal comprador de produtos brasileiros e de fornecedor (BRASIL, 2014).

A inserção internacional comercial brasileira sofreu mudanças significativas a partir da ascensão chinesa, com alterações substanciais na dinâmica, padrão e direcionamento de seu comércio exterior. Bilateralmente, o padrão comercial sino-brasileiro entre 1980 e 1990 era destacadamente dado pelas exportaçóes brasileiras de manufaturados e a importação de matérias-primas agrícolas, minerais e metais. Ao longo dos anos 2000, essa conformação se inverteu, e os brasileiros tornaram-se grandes exportadores de produtos básicos e importadores de manufaturados. Dados consolidados do governo brasileiro já registravam que, ao final da década de 2000, dos produtos exportados pelo Brasil à China, 83,7\% eram básicos, destacadamente commodities agrícolas e minerais, enquanto $97,5 \%$ dos importados eram manufaturados (BRASIL, 2014).

A forte demanda da China por produtos brasileiros, principalmente soja e minério de ferro, contribuiu para que os produtos básicos, que representavam $22,8 \%$ do total das exportaçóes brasileiras em 2000, passassem a responder, em 2013, por $46,7 \%$ (BRASIL, 2014). Esse processo, se considerada somente a pauta de exportaçôes, pode ser interpretado como uma reprimarização ou especialização regressiva do padrão comercial do país. Porém, a profunda mudança no padrão comercial brasileiro, em decorrência da ascensão chinesa, não foi apenas bilateral, mas também geral, uma vez que existem evidências empíricas de que as exportações industriais chinesas também deslocam seus rivais brasileiros de mercados externos, agravando a perda de dinamismo de nossa produção industrial (CUNHA et al., 2012).

A configuração comercial sino-brasileira estabelecida nos últimos anos de certa forma também encontra respaldo no próprio perfil de inserção produtiva dos chineses no Brasil, o que tem ocorrido via investimentos diretos estrangeiros destinados a fusões ou aquisições de empresas brasileiras. Segundo Fraga (2013), entre 2009 e 2012, a China foi a principal origem de investimentos para fusões e aquisições no Brasil, respondendo por $16,1 \%$ do total realizado. Esse percentual contrasta de forma significativa com sua participação anterior, que, entre 2005 e 2008, foi de apenas $0,1 \%$. Com um volume de US\$21,5 bilhões investidos no 
período de 2009 a 2012, os chineses concentraram 77\% deste montante em setores relacionados a commodities e suas cadeias, principalmente extração de petróleo e gás natural (FRAGA, 2013).

A nova configuração de padrão comercial do Brasil e o perfil da inserção dos chineses em sua economia nacional a partir da estratégia de desenvolvimento daquele país têm sido acompanhados de argumentações favoráveis e desfavoráveis, com maior ênfase para as últimas. O ponto positivo normalmente destacado é o de que a forte demanda da China por produtos - insumos - nos quais o Brasil é competidor, tais como as commodities agrícolas e minerais, não apenas possibilitou um grande avanço das exportações brasileiras, com registro de sucessivos recordes, mas também influenciou a alta dos preços desses produtos, que, nos últimos tempos, foi responsável por sustentar os superávits comerciais do país, inclusive em momentos de crise internacional. Além disso, alguns pesquisadores trabalham com a hipótese de que a importação de bens finais e equipamentos chineses pode favorecer a modernização da indústria no Brasil (JENKINS; BARBOSA, 2006). Por outro lado, observa-se a forte demanda brasileira, via importaçôes, por produtos manufaturados de origem chinesa, desencadeando reações temerárias de vários setores industriais brasileiros capitaneados pela Fiesp - Federação das Indústrias do Estado de São Paulo.

Para as representações de vários setores industriais, como Associação Brasileira da Indústria Têxtil (Abit), Associação Brasileira da Indústria de Máquinas e Equipamentos (Abimaq), Associação Brasileira da Indústria de Elétrica e Eletroeletrônica (Abinee), Associação Brasileira da Indústria de Brinquedos (Abrinq), entre outras, a inserção comercial manufatureira chinesa no Brasil tem contribuído para a desindustrialização do país, dado que a manufatura nacional tem sido preterida pelos importados, especialmente os oriundos da China, em que o fator preço normalmente é imputado como principal motivador. A fundamentação desse discurso tem o seu respaldo dado atualmente na forte participação das importações chinesas em setores estratégicos, como o de eletroeletrônicos e metal-mecânico, que atingiram níveis históricos do consumo nacional.

Essa trajetória de maximização da relação custo-benefício, segundo a Fiesp (2010), não tem sido algo proporcionado exclusivamente pela variável cambial, que repercute diretamente no preço dos bens, mas sim o resultado de uma mudança estrutural da competitividade internacional chinesa. Para esta Federação, assim como para outras entidades de classes, a exemplo da Abimaq (2012), a recepção de investimentos diretos estrangeiros majoritariamente destinados a fusões e aquisições, em que a China também se destaca, trata-se de uma realidade em curso que carac- 
teriza um processo de desnacionalização da indústria nacional diante da ascensão dos chineses. Para Cano (2012, p. 834), tais resultados são não apenas evidentes, mas também reveladores dos efeitos danosos às cadeias produtivas brasileiras da inserção internacional chinesa, cujos resultados em grande parte conformam uma "desindustrialização precoce e nociva" de "sentido regressivo do progresso econômico" do Brasil.

\section{Desafios para uma agenda brasileira de desenvolvimento: lições chinesas}

Dada a crescente presença de produtos chineses no mercado brasileiro e as transformaçōes que aquele país tem propiciado à geografia econômica internacional, o Brasil é compelido a questionar sobre quais os novos caminhos e estratégias que deve tomar diante dessa nova realidade. A questão não é simples de ser resolvida com dicotomias entre especialização minério-agrícola versus proteção industrial, ou ainda a mera adoção, ou replicação, de políticas ou estratégias industriais isoladas. Pelo contrário, tal situação suscita reflexões mais profundas, direcionadas, sobretudo, a um realinhamento estratégico a partir de uma visão de futuro, que vislumbre e consolide uma identidade nacional. Para isso, faz-se necessário um entendimento do Brasil, sua estrutura e competências produtivas, e, a partir da geografia político-econômica constituída, inferir quais oportunidades são possíveis de serem exploradas e, principalmente, quais as diretrizes, fundamentos e meios são os mais adequados para sua consecução.

A experiência da recente rápida industrialização chinesa pode ser útil para repensar o caso brasileiro, sua trajetória ao longo do século XX e sua entrada no $\mathrm{XXI}$, pois, diferentemente dos chineses, as tentativas brasileiras de estabelecer uma estratégia nacional de desenvolvimento têm se caracterizado pela descontinuidade. Analisando os períodos recentes, posteriores aos anos 1990, vislumbram-se na economia brasileira políticas isoladas, não totalmente articuladas, que tentaram resolver problemas específicos, principalmente os fiscais, cambiais ou inflacionários, mais de ordem macroeconômica conjuntural do que estrutural.

$\mathrm{Na}$ questão industrial, central para o desenvolvimento econômico, conforme salientado neste artigo, a situação é mais proeminente. Embora o Brasil tenha optado recentemente por um caminho contrário aos receituários do Consenso de Washington, buscando, como a China, uma participação governamental mais ativa em sua economia, constatam-se dificuldades para implementar uma política estatal de 
médio e longo prazos, com capacidade de articulação de seus atores. Alguns esforços foram timidamente empreendidos na última década, como a Política Tecnológica, Industrial e de Comércio Exterior (PITCE), em 2004, a Política de Desenvolvimento Produtivo (PDP), em 2008, e recentemente o Plano Brasil Maior (PBM), em 2012. Porém, ainda que todas consigam apresentar um diagnóstico pertinente do país, tais políticas não atingiram resultados expressivos.

A PITCE foi formulada em um contexto de estagnação da atividade produtiva e marcou o retorno das políticas industriais no Brasil, apostando em setores de alto potencial tecnológico, em especial bens de capital, fármacos, semicondutores e softwares, que em tese seriam capazes de gerar externalidades positivas para o restante da indústria. Entretanto, muito pouco do que estava previsto foi efetivamente implementado ou articulado. Seu principal legado foi a institucionalização de uma legislação mais amigável aos investimentos em P\&D (Lei do Bem, Lei da Inovação), assim como a construção de algumas arenas decisórias formuladoras de política industrial com a participação conjunta de instituições públicas e importantes grupos empresariais, como a Associação Brasileira para o Desenvolvimento Industrial (ABDI) e o Conselho Nacional de Desenvolvimento Industrial (CNDI).

Após tais iniciativas, uma nova versão da política industrial foi proposta, a PDP. Se, por um lado, essa nova política industrial fora construída em um ambiente econômico mais favorável e de forma mais articulada à iniciativa privada, por outro, faltou-lhe seletividade setorial, articulação e o estabelecimento de contrapartidas claras a serem oferecidas pelas empresas ao grande volume de crédito público que lhes foi concedido. Com isso, seus principais resultados positivos foram os aumentos do emprego industrial e da taxa de investimento nacional, embora a elevação desta última tenha ocorrido de forma temporária, aquém da meta prevista e concentrada nos setores produtivos tradicionais, com fraco desempenho em termos de diversificação produtiva para atividades mais intensivas em conhecimento.

Por seu turno, o último documento de política industrial, o Plano Brasil Maior, buscou dar maior ênfase às atividades inovadoras e uma melhor inserção externa do país, via adensamento das cadeias produtivas e aumento das exportaçóes de manufaturados. Em certa medida, este Plano parece ter incorporado, ainda que tardiamente, as novas dinâmicas da competitividade internacional - como a China já havia se antecipado anos antes. Nesse quesito, um dos pontos de destaque de seu marco estratégico foi a questão das políticas de apoio à internacionalização de maneira mais explícita no país. 
Nesse sentido, o Plano preconizou a diversificação das exportações (mercados e produtos) e a internacionalização corporativa, colocando como objetivos do governo federal: "a promoção de produtos manufaturados de tecnologias intermediárias e de fronteiras intensivos em conhecimento"; o "aprofundamento do esforço de internacionalização de empresas nacionais líderes em commodities para empresas líderes com capacidade de diferenciação de produto, agregação de valor e acesso a novas tecnologias"; e o "enraizamento de empresas estrangeiras objetivando a instalação de centros de $\mathrm{P} \& \mathrm{D}$ no país para a adoção das melhores práticas produtivas" (BRASIL, 2011, p. 16).

Porém, ainda que com uma proposta mais contemporânea, com claras influências das experiências asiáticas, não foram implementados instrumentos e ações capazes de efetivá-la. Com relação a isso, algumas observações são plausíveis. É importante destacar novamente a questão conjuntural. Afinal, ao longo da implantação do Plano, houve forte arrefecimento da economia doméstica, com lenta recuperação da economia global pós-crise de 2008. Além disso, os resultados da estratégia chinesa, que culminaram na intensificação da participação das importaçôes industriais no Brasil, compeliram o governo brasileiro a tomar medidas mais imediatas, optando, em vez de uma perspectiva estrutural, pelo retorno às açôes protecionista de curto prazo.

Nesse contexto, embora seja relevante ressaltar tais questôes de conjuntura, é fundamental considerar que a ideia de uma estratégia de desenvolvimento pressupooe, justamente, o rompimento com o horizonte de curto prazo. É pertinente assumir que os resultados insatisfatórios das experiências brasileiras recentes de desenvolvimento com foco industrial, em particular o $\mathrm{PMB}$, não se tratou de um problema apenas de cenário, mas também de lógica de funcionamento das políticas industriais no Brasil. Assim, não obstante o PMB tenha tido um marco estratégico validado nacionalmente, e o mais bem elaborado das últimas décadas, assistiu-se, ao longo de sua implementação, a medidas contrárias às diretrizes estabelecidas, que relevaram uma grande fragilidade: a falta de articulação governamental e o isolamento ativo de importantes agentes do Executivo.

Exemplo notório de tal dinâmica pode ser dado pelo papel assumido pelo BNDES. Afinal, durante a vigência da PDP, o BNDES foi o principal articulador da projeção internacional de grandes grupos de capital majoritariamente nacional em setores tradicionais, como processamento de carnes, mineração, aço, petroquímica e papel e celulose. Porém, a despeito da mudança de proposta contida no PBM, de privilegiar a internacionalização de setores mais intensivos em tecnologia, o que se observou efetivamente foi a retração total dos desembolsos do Banco destinados 
à internacionalização das empresas de quaisquer setores durante a vigência dessa política (CASEIRO; MASIERO, 2014).

Ainda como sintomas da baixa articulação do poder público em torno da internacionalização de empresas, é possível constatar, a partir de 2004, a paralisação do estabelecimento de acordos internacionais para evitar a dupla tributação e de proteção bilateral dos investimentos das multinacionais, justamente quando a internacionalização passou a ser foco das políticas industriais brasileiras. O Brasil possui apenas 29 acordos para evitar a dupla tributação dos investimentos, ao passo que os acordos de proteção bilateral dos investimentos foram vetados pelo Congresso Brasileiro em 2003 por serem considerados uma ameaça à soberania nacional (SENNES; MENDES, 2009). A descontinuidade das políticas de internacionalização também é evidente em algumas ações hesitantes do Ministério da Fazenda (MF), que, em agosto de 2013, passou a tributar os lucros das empresas brasileiras no exterior que pagavam alíquotas menores às existentes no Brasil, impondo uma perda de competitividade em relação às suas concorrentes nos mercados externos - tanto que, em outubro de 2014, o MF revisou essa medida.

Tais exemplos são notórios para revelar a desarticulação das diferentes esferas do poder público brasileiro em relação aos objetivos das políticas industriais propostas. Por um lado, é possível afirmar que os diversos ensaios de política industrial realizados pelo Brasil ao longo das últimas décadas trouxeram um legado positivo ao possibilitarem uma retomada da capacidade governamental de planejamento e implementação políticas de larga escala com vistas ao desenvolvimento econômico. Por outro lado, os objetivos de longo prazo da política industrial, que só podem ser alcançados via articulação, que dizem respeito à constituição de novas capacidades produtivas em atividades de maior valor agregado, não foram priorizados ou adequadamente conduzidos. Com isso, as adversidades conjunturais, frequentemente utilizadas no país como justificativa para a incapacidade de cumprimento das diretrizes das políticas industriais, só serão superadas justamente pela transformação estrutural de longo prazo do tecido produtivo, objeto original - e principal - da política industrial.

Nesses termos, é compreensível a existência no Brasil de forte debate sobre a pertinência ou não de política industriais como estratégia de desenvolvimento nacional. Afinal, a despeito das iniciativas realizadas nesse sentido nas últimas décadas, seus resultados, por vezes decepcionantes, acabam por nutrir análises contrárias à sua formulação e implementação. Porém, quando analisadas as trajetórias de desenvolvimento bem-sucedidas de outros países e, recentemente, da China, algumas 
lições ao Brasil são importantes de serem consideradas. Primeiramente, como o caso asiático demonstra na virada do século, não se trata de pensar ou não a participação do Estado na condução de uma estratégia nacional de desenvolvimento. Tanto a experiência asiática quanto a de outros países em desenvolvimento demonstram que, mesmo diante de um mundo global, o Estado é extremamente relevante e fundamental. O ponto focal, nesse caso, é a forma como a sua intervenção deve ocorrer.

$\mathrm{E}$, nesse contexto, algumas diretivas devem ser consideradas quando da defesa das ações governamentais para indução do crescimento via políticas industriais no cenário global contemporâneo. Em particular, ressalta-se o alerta provisionado pela argumentação de corte mais liberal, segundo a qual as políticas industriais podem se tornar um canal de clientelismo, corrupção do poder público e alocação ineficiente de recursos (PACK; SAGGI, 2006). Nesse sentido, uma série de medidas concretas deve ser tomada para evitar tais riscos, maximizando as chances de sucesso deste tipo de política, o que inclui: ação coordenada e coerente das diferentes instituições, políticas e programas estatais em relação ao escopo da estratégia de desenvolvimento perseguida; estabelecimento de critérios objetivos para seleção dos setores e empresas beneficiadas pela política industrial; exigência de contrapartidas a serem garantidas por esses setores e empresas, tais como a ampliação dos investimentos em capital físico e em pesquisa, desenvolvimento e inovação (P\&D\&I), o aumento da produtividade e a diversificação da produção em setores mais intensivos em conhecimento; e, por fim, imposição de um limite temporal para o término do auxílio estatal às empresas beneficiadas, associado à consecução dos objetivos propostos (AMSDEN, 2009; EVANS, 2004; RODRIK, 2004).

Com isso, diante do desafio contemporâneo de transitar com autonomia de um tecido industrial fortemente apoiado em setores de baixa e média intensidade tecnológica para uma economia intensiva em conhecimento, é possível vislumbrar uma posição favorável à economia brasileira, tendo em vista sua estrutura industrial e capacidade empresarial já constituídas e o porte de seu mercado interno, caso incorporadas algumas liçôes chinesas sob a ótica de participação ativa do Estado na indução dessa transformação, com foco na competitividade internacional por meio de políticas públicas articuladas.

Em primeiro lugar, a experiência chinesa demonstrou que o financiamento público à expansão de empresas privadas ou estatais deve estar condicionado a contrapartidas empresariais claras e alinhadas aos objetivos da política industrial. Se as restrições impostas pela OMC a metas de desempenho exportador impedem a adoção das estratégias realizadas pela Coreia e pelo Japão no passado, ainda resta a 
possibilidade de contrapartidas relacionadas à ampliação do investimento doméstico e à diversificação produtiva para setores mais intensivos em conhecimento, como foi o caso implantado recentemente pela China.

Em segundo lugar, o exemplo chinês revela que o Brasil pode e deve utilizar a força de seu mercado interno para negociar a atração e a incorporação de tecnologias estrangeiras ao seu parque industrial. Não se trata de restringir o investimento direto, mas sim de promover uma atuação governamental proativa e orquestrada para oferecer benefícios seletivos, buscando atrair empresas de alta tecnologia e com elevada capacidade exportadora mediante incentivos de transferência tecnológica e de desenvolvimento de fornecedores locais. Inclusive, o Brasil já implementou com sucesso tal estratégia no passado, desenvolvendo uma pujante indústria de autopeças e de bens de capital, com projeção regional e até mesmo global, mas que vê sua competitividade internacional cada vez mais ameaçada pela falta de continuidade e desarticulação. Nesse sentido, é preciso olhar para o futuro, além da proteção dos setores já estabelecidos, para a criação de novos encadeamentos produtivos em atividades de grande potencial tecnológico, tanto em áreas nas quais o Brasil já possui alguma base de competências, como biotecnologia, fármacos, TICs, energias renováveis e materiais compósitos, quanto naquelas em que as capacidades nacionais, tecnológicas e humanas ainda precisam ser construídas, como nanotecnologia, robótica e manufatura aditiva.

Em terceiro lugar, a trajetória da China expõe a importância da seletividade da política industrial e da necessidade de ousadia na implementação de grandes projetos estruturantes em setores intensivos em conhecimento, com encadeamentos positivos para o restante da economia. A necessidade de construção de capacidades produtivas não deve ser vista como um elemento proibitivo, mas sim como um elemento resultante de uma articulação bem desenhada entre público e privado. Assim como a China foi capaz de encarar com sucesso o desafio de erguer empresas de alta tecnologia controladas pelo capital nacional e outras com participação privada nas últimas décadas, o Brasil também já realizou tal proeza no passado, tanto com a indústria petroquímica quanto com a aeronáutica. No início da década de 2000, a indústria naval foi retomada com grande ímpeto, graças a esforços da política industrial, e com grande impacto positivo para a indústria de fornecedores, especialmente no Nordeste do país. Porém, atualmente o modelo brasileiro ficou ultrapassado e dicotômico entre Estado e mercado. É possível avançar com mais ousadia em outros setores industriais, como os supracitados, em uma nova dinâmica articulada. Nesse sentido, é fundamental que o BNDES não esteja submetido a uma 
lógica de balcão de concessão de crédito por meio da simples avaliação da viabilidade financeira de projetos, mas utilize sua capacidade de desembolso de forma alinhada a uma estratégia de transformação estrutural, que almeje uma economia mais intensiva em conhecimento e de alta produtividade.

Nesses termos, destacam-se diretivas que emergem de um ponto central, a principal lição: a transformação estrutural do tecido industrial brasileiro por meio de uma política industrial de grande porte somente será possível pela articulação orquestrada dos diferentes agentes do poder público em parceria com a iniciativa privada. Tal elemento é essencial tanto para a transmissão de confiança e de incentivos inequívocos aos investimentos empresariais, quanto para a efetiva implementação das diretrizes e intenções contidas nos documentos de política industrial. Para isso ocorrer, é necessário que a política industrial de longo prazo seja elevada à condição de prioridade nacional, deixando de ser submetida, e muitas vezes bloqueada, por restrições de ordem conjuntural.

\section{Considerações finais}

É possível concluir que as oscilações dos rumos das mais recentes políticas industriais brasileiras e seus baixos resultados não constituem algo exclusivamente das turbulências do mercado internacional ou das instabilidades da economia doméstica como normalmente se apregoa, mas sim trata-se de um problema evidente de fundamentos. Afinal, os problemas de implantação e resultados no Brasil revelam a dificuldade nacional de o Estado brasileiro promover a coesão e a articulação de seus próprios atores institucionais e destes com os empresariais sob um mesmo marco estratégico e de ação, focado no desenvolvimento de longo prazo associado à competitividade internacional.

Nesse sentido, para concepção de uma estratégia de desenvolvimento para o Brasil, a experiência chinesa recente sugere vários aprendizados. Basicamente, ela revela que o crescimento industrial é uma etapa necessária ao desenvolvimento e ao alinhamento com as dinâmicas competitivas contemporâneas, cujo foco se sustenta na internacionalização e nas cadeias globais de valor; caso contrário, o modelo de substituição das importações ainda seria um caminho sustentável. A necessidade de se vincular e se posicionar internacionalmente é fator imprescindível. Porém, isso só é passível de ser realizado se for de maneira articulada entre os agentes estatais e os de mercado em uma perspectiva de longo prazo. 
Conclui-se, pelo exposto, que o Brasil necessita despertar e aprofundar o debate em torno das formas e desenhos institucionais mais adequados para articular agentes públicos e privados no esforço de pensar o futuro do país. Isso deve ser feito a partir de uma nova realidade e geografia econômica, passando a assumir que as políticas governamentais mais apropriadas no atual contexto não são necessariamente as mesmas de outrora em seus setores e métodos, tampouco a réplica de outras sem as devidas adequações e priorizações diferenciadas. $\mathrm{O}$ foco deve recair na articulação de diretrizes e esforços de longo prazo com instituições de compliance e accontability capazes de direcionar a economia brasileira em ampla frente governamental e privada, visando a dinamização de seus negócios nacionais e internacionais. O Brasil, a exemplo da China, precisa traçar sua própria estratégia, priorizando maior articulação de políticas, inovação tecnológica e internacionalização de suas empresas e economia.

\section{Referências bibliográficas}

ABDI - Agência Brasileira de Desenvolvimento Industrial. Política industrial de países selecionados: Brasil, Rússia, Índia e China. Política Industrial Comparada, v. 10, 2011. Disponível em: <www.abdi.com.br>. Acesso em: 21 dez. 2014.

AMSDEN, A. H. A ascensão do resto. São Paulo: Unesp, 2009.

ABIMAQ - Associação Brasileira da Indústria de Máquinas e Equipamentos. Desindustrialização + desnacionalização: um risco à soberania. 2012. Disponível em: <http://www. fieb.org.br/Adm/FCKimagens/file/Conselhos/2012/Agosto/ABIMAQ\%204\%20-\%20 Desnacionalizac\%CC\%A7a\%CC\%83o.pdf>. Acesso em: 01 mar. 2013.

BNDES - Banco Nacional de Desenvolvimento Econômico e Social. Perspectivas do investimento e da política industrial nos BRICS. Projeto PIB - Perspectivas do Investimento no Brasil. Belo Horizonte, 2009. Disponível em: <www.bndes.gov.br>. Acesso em: 22 dez. 2014. BHATTACHARYA, A.; MICHEL, D. How local companies keep multinationals at bay. Harvard Business Review, v. 86, n. 3, p. 84-94, 2008.

BOLT, J.; ZANDEN, J.L. The first update of the Maddison Project, Re-estimating growth before 1820. Jan. 2013. (Maddison Project working paper, 4).

BRASIL. Brasil Maior - Plano 2011/2014. Texto de referência. Brasília, 2011. Disponível em: $<$ http://www.brasilmaior.mdic.gov.br/wp-content/uploads/2011/11/plano_brasil_maior_texto_de_referencia_rev_out11.pdf>. Acesso em: 02 jan. 2014. 
BRASIL. Ministério do Desenvolvimento, Indústria e Comércio Exterior - MDIC. Sistema Aliceweb. 2014. Disponível em: <aliceweb2.mdic.gov.br>.

BUIRA, A. The dogmatism of Washington Consensus. In: TEUNISSEN, J. J.; AKKERMAN, A. (Eds.). Diversity in development: reconsidering the Washington Consensus. The Hague: FONDAD, 2004. Disponível em: <http://www.fondad.org/uploaded/Diversity\%20in\%20 Development/Fondad-Diversity-Contents-Contributors.pdf>. Acesso em: 20 maio 2012. CANO, W. A desindustrialização do Brasil. Economia e Sociedade, v. 21, número especial, p. 831-851, 2012.

CASEIRO, L. C. Z.; MASIERO, G. OFDI promotion policies in emerging economies: the Brazilian and Chinese strategies. Critical Perspectives on International Business, v. 10, n. 4, p. 237-255, 2014.

CASTELLS, M. A sociedade em rede. 2. ed. São Paulo: Paz e Terra, 1999.

CASTRO, A. B. No espelho da China. Campinas: Unicamp, 2011 (Texto para discussão). Disponível em: <http://www.gr.unicamp.br/ceav/content/pdf/pdf_textobrasilnoespelhodachina.pdf>. Acesso em: 02 maio 2012.

CSY - China Statistical Yearbook. National statistical database 2009. 2010.

CUNHA, A. M. et al. O Brasil no espelho da China: tendências para o período pós-crise financeira global. Revista de Economia Contemporânea, v. 16, n. 2, p. 208-236. 2012.

DICKEN, P. Mudança global: mapeando as novas fronteiras da economia mundial. 5. ed. Porto Alegre: Bookman, 2010.EVANS, P. Autonomia e parceria: Estados e transformação industrial. Rio de Janeiro: Editora UFRJ, 2004.

FIESP - Federação das Indústrias do Estado de São Paulo. Manifesto - Grito de Alerta. Disponível em: <http://www.fiesp.org.br/gritodealerta>. Acesso em: 20 nov. 2012.

FIESP - Departamento de Competitividade e Tecnologia - Decomtec. Análise da penetração das importações chinesas no mercado brasileiro. Abril 2010. Disponível em: <http://www. fiesp.com.br/competitividade/downloads/fiesp \%20penetração\%20dos $\% 20$ produtos $\% 20$ chineses\%20no\%20mercado\%20brasileiro\%20110414.pdf>. Acesso em: 15 abr. 2012.

FRAGA, E. China lidera aquisiçóes de empresas brasileiras. Folha de S. Paulo, 01 de março de 2013. Disponível em: <http://www1.folha.uol.com.br/fsp/mercado/96235-china-lidera-as-aquisicoes-de-empresas-brasileiras.shtml>. Acesso em: 22 maio 2014.

GAO, Y. China as the workshop of the world. Cambridge: Routledge, 2011. 
GHEMAWAT, P.; HOUT, T. Tomorrow's global giants? Not the usual suspects. Harvard Business Review, v. 86, n. 11, p. 80-96, 2008.

HALL P. A., SOSKICE D. Varieties of capitalism: the institutional foundations of comparative advantage. Oxford: Oxford University Press, 2001.

JENKINS, R.; BARBOSA, A. F. Fear for manufacturing? China and the future of industry in Brazil and Latin America. The China Quarterly, v. 209, p. 59-81, 2006.

KRÜGER, J. J. Productivity and structural change: a review of the literature. Journal of Economic Surveys, v. 22, n. 2, p. 330-363, 2008.

MAcDONALD, S.; LEMCO, J. Asia's rise in the 21st century. 1. ed. Westport: Praeger Publishers, 2011.

MARRONE, P. China e seus efeitos sobre a induistria de máquinas e equipamentos do Brasil. São Paulo: Magma Cultural, 2006.

MASIERO, G.; COELHO, D. B. A política industrial chinesa como determinante da estratégia going global. Revista de Economia Política, v. 34, n. 1, 2014.

MASIERO, G. et al. Competitividade industrial chinesa: impacto econômico e realidade socioambiental. 1. ed. Curitiba: Juruá Editora, 2012.

MIAO, C.; WEI, Y. D.; MA, H. Technological learning and innovation in China in the context of globalization. Eurasian Geography and Economics, v. 48, n. 6, p.713-732, 2007.

NOLAN, P. China and the global economy: national champions, industrial policy, and the big business revolution. Great Britain: Palgrave, 2001.

. Globalisation and industrial policy: the case of China. The World Economy, v. 37, n. 6, p. 747-764, 2014.

PACK, H.; SAGGI, K. The case for industrial policy: a critical survey. 2006 (World Bank Policy Research Working Paper, n. 3839). Disponível em: <http://www-wds.worldbank. org/servlet/WDSContentServer/WDSP/IB/2006/01/31/000016406_20060131160754/ Rendered/PDF/wps3839.pdf>. Acesso em: 29 set. 2013.

PORTER, M. E. A vantagem competitiva das naçôes. 14. ed. Rio de Janeiro: Elsevier, 1989. REUTERS. Fiesp mira China antes de visita de Dilma Rousseff ao país. Folha de S. Paulo, 22/02/2011. Disponível em: <http://www.folha.com.br/me879590>. Acesso em: 5 maio 2012.

RODRIGUEZ, F. Openness and growth: what have we learned? New York: United Nations, August 2007 (DESA working paper, n. 51). Disponível em: <http://www.un.org/esa/desa/ papers/2007/wp51_2007.pdf>. Acesso em: 10 mar. 2012. 
RODRIK, D. Industrial policy for the twenty-first century. Cambridge, MA, 2004 (Research paper - UNIDO). Disponível em: <http://www.hks.harvard.edu/fs/drodrik/Research\%20 papers/UNIDOSep.pdf>. Acesso em: 04 jun. 2012.

SENNES, R.; MENDES, R. C. Políticas públicas e as multinacionais brasileiras. In: RAMSEY, J.; ALMEIDA, A. (Orgs.). A ascensão das multinacionais brasileiras: o grande salto de pesopesados regionais a verdadeiras multinacionais. Rio de Janeiro: Elsevier, 2009.

SOETE, L. From industrial to innovation policy. Journal of Industrial, Competition and Trade, v. 7, n. 3, p. 273-284, 2007.

UNCTAD - United Conference on Trade and Development. Statistic database. 2010. Disponível em: <http://unctadstat.unctad.org>. Acesso em: 16 mar. 2012.

. World investment report 2006. 2006. Disponível em: <http://www.unctad.org/ en/docs/wir2006_en.pdf>. Acesso em: 16 mar. 2012.

VIETOR, R. H. K. How countries compete: strategy, structure, and government in the global economy. Boston: HBS Press, 2007.

WADE, R. H. After crisis: industrial policy and development state in low-income countries. Global Policy, v. 1, n. 2, p.150-161, 2010.

WORLD BANK. China 2030. 2012. Disponível em: <http://www.worldbank.org/content/ dam/Worldbank/document/China-2030-complete.pdf>. Acesso em: 10 mar. 2012.

. Statistic data base. 2013. Disponível em: <http://data.worldbank.org/>.

WTO - World Trade Organization. Statistic database. 2011. Disponível em: <http://stat. wto.org>. Acesso em: 8 dez. 2011.

ZENG, M.; WILLIAMSON, P. Dragons at your door: how Chinese cost innovation is disrupting global competition. Cambridge: Harvard Business School Press, 2007. 
